\title{
Variasi Teknologi Pengurangan Kesadahan Dalam Pengolahan Air Minum
}

\author{
Oleh Gede H. Cahyana
}

\begin{abstract}
Abstrak
Secara ekonomi, air sadah merugikan karena memboroskan penggunaan sabun natrium. Air sadah ini dapat dibedakan menjadi dua, yaitu air sadah temporer dan air sadah permanen. Yang bisa dihilangkan dengan pemanasan adalah air sadah temporer sedangkan air sadah permanen harus dengan proses kapur-soda, ion exchanger atau demineralisasi. Persyaratan kualitas kesadahan air industri tertentu lebih tinggi daripada air minum sehingga terapan teknologinya berbeda. Air untuk proses industri tertentu perlu ion exchanger menggunakan resin agar tidak terjadi scaling di dalam peralatannya.
\end{abstract}

Kata Kunci: sadah, softening, kapur-soda, scaling, ion exchanger

\section{Pendahuluan}

Kekerasan, tindakan anarkhistis, main hakim sendiri, pasti tidak disukai oleh masyarakat. Di PDAM pun tidak diharapkan terjadi kekerasan. Begitu juga "kekerasan" di dalam air yang disebut hardness. Kalau tinggi kadar hardness di dalam air baku PDAM, maka tinggi pula biaya operasi-rawat instalasinya sehingga mengurangi laba bersihnya. "Kekerasan" air ini seolah-olah musuh bagi PDAM sehingga harus "dimusnahkan" atau dikurangi sampai batas yang diizinkan oleh baku mutu air minum demi kesehatan pelanggannya.

Tak hanya dampak kesehatan, kerugian ekonomi pun terjadi lantaran hardness. Banyak ibu rumah tangga mengeluh karena panci dan ketelnya cepat berkerak dan kotor. Kalau dicuci dan digosok terlalu keras malah bocor. Inilah salah satu dampak buruk "air keras" terhadap peralatan dapur yang sering digunakan untuk memanaskan air. Dampak berikutnya ialah boros sabun mandi. Sebab, sabun natrium (sodium soap) lebih dulu bereaksi dengan kation penyebab hardness (kesadahan) dan membentuk endapan sehingga tidak bisa berbusa sampai semua ion kesadahannya habis bereaksi. Reaksinya sbb:

$2 \mathrm{NaCO}_{12} \mathrm{C}_{17} \mathrm{H}_{33}$ (sabun) + Kation Kesadahan $\rightarrow \mathrm{Kat}\left(\mathrm{CO}_{12} \mathrm{C}_{17} \mathrm{H}_{33}\right)_{2} \downarrow$ (endapan) $+2 \mathrm{Na}^{+}$.

Parahnya lagi, endapan itu dapat melekat dan mengotori serat kain, porselen, keramik, dan alat plambing seperti wastafel, kloset, bathtub, urinal, dan lain-lain. Selain disinyalir bisa 
menyumbat pori-pori kulit sehingga terasa kasar dan tidak nyaman, air sadah pun dikaitkan dengan penyempitan pembuluh darah dan penyakit jantung (kardiovaskuler).

Tidak hanya PDAM yang direpotkan oleh kesadahan. Di pabrik yang menggunakan boiler atau pemanas air pun terjadi hal serupa. Malah dampaknya lebih berbahaya, yaitu bisa meledak. Ledakan terjadi kalau endapan di dalam dinding boiler itu tidak merata sehingga tekanannya terus membesar dan tidak setimbang (merata). Di bagian yang banyak endapan (kerak) akan bertekanan lebih besar daripada bagian dinding lainnya sehingga potensial meletus. Di dalam pipa air panas (hot water supply) yang ada di hotel atau villa pun terjadi hal demikian. Penggantian pipa lantas terpaksa sering dilakukan sebelum usia desainnya tercapai.

Separah itukah dampak air sadah? Betul, semuanya bisa terjadi. Itu sebabnya air pengisi boiler haruslah air yang bebas-sadah. Kalaupun sadah, harus serendah-rendahnya untuk menghindari pengerakan. Dengan kata lain, syarat kesadahan air ketel lebih ketat ketimbang air minum, yaitu maksimum satu derajat Jerman. Biasanya ditulis $1^{\circ} \mathrm{G}$ ( $\mathrm{G}=$ Germany) atau $\mathrm{D}$ (Deutsch). Satu derajat Jerman setara dengan $10 \mathrm{mg} / \mathrm{l} \mathrm{CaO}$ atau $17,9 \mathrm{mg} / \mathrm{l} \mathrm{CaCO}_{3}$. Sebaliknya pada air minum dipersilakan kesadahannya antara $5-10^{\circ} \mathrm{G}$. Hanya saja, dalam keputusan Menteri Kesehatan yang berlaku sekarang, besarnya kesadahan sampai 500 mg/l tetapi tidak dijelaskan satuannya apakah $\mathrm{CaCO}_{3}$ ataukah $\mathrm{CaO}$ atau yang lainnya.

Apabila dirujuk ke buku teks, ada pembagian taraf kesadahan. Biasanya dikelompokkan menjadi empat kategori. Yang kesatu, disebut air lunak (soft) dengan kesadahan kurang dari $50 \mathrm{mgl} / \mathrm{CaCO}_{3}$. Kedua, kesadahan sedang, dengan nilai kesadahan antara 50 - $150 \mathrm{mg} / \mathrm{l}$ $\mathrm{CaCO}_{3}$. Ketiga, kesadahan keras, antara $150-300 \mathrm{mg} / \mathrm{CaCO}_{3}$, dan keempat sangat keras, yakni lebih dari $300 \mathrm{mg} / / \mathrm{CaCO}_{3}$. Artinya, batas maksimum keputusan Menteri Kesehatan yang berlaku sekarang (nomor 907/Menkes/SK/2002) jauh di atas "sangat keras" (very hard). Tidakkah ini keliru? Adakah penjelasan lainnya?

\section{Penyadahan}

Air sadah berasal dari air hujan yang melewati formasi geologi atau lapisan batu kapur. Konsentrasinya berbeda-beda, ada yang besar, ada yang kecil. Yang besarlah yang menjadi masalah karena harus diolah dengan cara pelunakan atau softening. Menurut definisinya, kesadahan ialah kehadiran kation multivalen (valensi 2 atau 3) berkonsentrasi tinggi di dalam air. Dari sekian banyak jenis kation itu, penyebab utamanya hanya kalsium dan magnesium. 
Yang lainnya ialah besi, mangan, timbal, barium, aluminum. Anion yang terlibat biasanya bikarbonat, sulfat, klorida, nitrat, dan silikat.

Bagaimana proses terjadinya air sadah? Proses ini tak lepas dari siklus hidrologi. Air hujan yang sampai ke Bumi, ada yang melimpas (run-off) ada juga yang meresap (infiltrasi) ke dalam tanah lalu mengalami perkolasi (menyusup) di lapisan tanah dalam. Ketika mengalir di lapisan tanah atas (top-soil), di dalam air terjadi aktivitas mikroba yang menghasilkan gas karbondioksida $\left(\mathrm{CO}_{2}\right)$. Air dan $\mathrm{CO}_{2}$ ini lantas membentuk asam karbonat $\left(\mathrm{H}_{2} \mathrm{CO}_{3}\right)$. Asam inilah yang kemudian bereaksi dengan batu kapur atau gamping $\left(\mathrm{CaCO}_{3}, \mathrm{MgCO}_{3}\right)$ menjadi kalsium bikarbonat, $\mathrm{Ca}\left(\mathrm{HCO}_{3}\right)_{2}$ dan magnesium bikarbonat, $\mathrm{Mg}\left(\mathrm{HCO}_{3}\right)_{2}$.

Berdasarkan komposisi ion-ionnya, kesadahan biasanya dibedakan menjadi dua, yaitu kesadahan sementara (karbonat atau temporer) dan kesadahan tetap (non-karbonat atau permanen). Kesadahan sementara disebabkan oleh kation yang bereaksi dengan anion $\mathrm{HCO}_{3}^{-}$(bikarbonat) dan sensitif terhadap pemanasan, langsung menimbulkan endapan pada temperatur tinggi. Endapannya ialah $\mathrm{CaCO}_{3}$ dan $\mathrm{Mg}(\mathrm{OH})_{2}$. Berikutnya, kesadahan tetap, disebabkan oleh anion sulfat, klorida, nitrat, silikat. Kesadahan ini tidak dapat dihilangkan dengan pemanasan tetapi harus direaksikan dengan kapur dan soda.

Berkaitan dengan konsentrasi kation dan anion pembentuk kesadahan, ada dua hal yang bisa terjadi. Yang pertama, konsentrasi bikarbonat lebih kecil daripada jumlah konsentrasi kation kalsium dan magnesium. Ini bisa ditulis $\left[\mathrm{HCO}_{3}^{-}\right]<\left(\left[\mathrm{Ca}_{2}^{+}\right]+\left[\mathrm{Mg}_{2}^{+}\right]\right)$. Akibatnya, di dalam air ada dua jenis kesadahan, yaitu kesadahan temporer dan kesadahan tetap. Nilai konsentrasi kesadahan temporer sama dengan konsentrasi $\mathrm{HCO}_{3}{ }^{-}$sedangkan kesadahan tetapnya sama dengan sisa konsentrasi kalsium dan magnesium yang tidak bereaksi dengan $\mathrm{HCO}_{3}^{-}$. Kesadahan tetap ditambah kesadahan sementara menghasilkan kesadahan jumlah atau kesadahan total.

Kemungkinan kedua, konsentrasi bikarbonatnya lebih besar daripada jumlah konsentrasi kalsium dan magnesium dan ditulis: $\left[\mathrm{HCO}_{3}{ }^{-}\right]>\left(\left[\mathrm{Ca}_{2}{ }^{+}\right]+\left[\mathrm{Mg}_{2}{ }^{+}\right]\right)$. Apabila kondisi ini yang terjadi maka di dalam air hanya ada kesadahan temporer (sementara). Semua kation $\mathrm{Ca}_{2}{ }^{+}$ dan $\mathrm{Mg}_{2}{ }^{+}$habis bereaksi dengan $\mathrm{HCO}_{3}^{-}$sehingga kesadahan temporernya sama dengan kesadahan total. 


\section{Softening}

Aspek sejarahnya, karena air sadah menimbulkan masalah, serentaklah perusahaan air minum di negara-negara bagian (state) Amerika Serikat beramai-ramai "memerangi" "kekerasan" air ini. Proses "perang" ini dinamai water softening atau pelunakan air. Biasa didefinisikan sebagai pemisahan mineral terlarut di dalam air yang menyebabkan kerak (scaling) di dasar panci, boiler (ketel), dan menimbulkan endapan di dalam pipa PDAM dan memboroskan sabun mandi. Mineral penyebab fenomena ini disebut ion penyebab sadah. Bagaimana di PDAM kita, sudahkah "menjinakkan" atau melunakkan air "kerasnya"?

Konsentrasi kesadahan juga mempengaruhi kecenderungan air untuk mengorosi pipa distribusi berbahan besi milik PDAM. Adapun kalangan industri lebih fokus pada pembentukan scaling (kerak) pada ketel uapnya, juga warna air dan rasa air yang dapat mempengaruhi produknya kalau berbahan baku air sadah. Industri, apalagi industri elektronika, biasanya mengolah air dengan kualitas yang lebih baik daripada air PDAM. Artinya, kalau airnya ada yang dipasok dari PDAM maka air PDAM itu pun diolah lagi khusus untuk menurunkan kekeruhan dan kesadahan, termasuk pembasmian bakteri.

Untuk menerapkan siasat dalam memerangi atau memisahkan ion penyebab sadah itu perlu diketahui hasil-kali kelarutannya (biasa ditulis $\mathrm{Ksp}$ ). Pada Tabel 1 disajikan hasil-kali kelarutan dan kelarutan garam-garam kalsium dan magnesium. Angka ini berguna untuk memperkirakan kecenderungan air yang mengandung ion kesadahan apakah akan menimbulkan kerak di dinding pipa, panci, dan ketel ataukah tidak.

Tabel 1. Kelarutan dan Ksp garam-garam penyebab air sadah.

\begin{tabular}{|c|c|c|c|}
\hline \multirow{2}{*}{ Senyawa } & \multicolumn{2}{|c|}{ Kelarutan (mg/l) } & \multirow{2}{*}{ Ksp } \\
\hline & Dingin & Panas $\left(25^{\circ} \mathrm{C}\right)$ & \\
\hline $\mathrm{CaCO}_{3}$ & 14 & 18 & $5 \times 10^{-9}$ \\
\hline $\mathrm{Ca}(\mathrm{OH})_{2}$ & 1.850 & 770 & $8 \times 10^{-6}$ \\
\hline $\mathrm{CaSO}_{4}$ & 2.090 & 1.620 & $2 \times 10^{-5}$ \\
\hline $\mathrm{MgCO}_{3}$ & 542.500 & 727.000 & - \\
\hline$\overline{\mathrm{Mg}(\mathrm{OH})_{2}}$ & 9 & 40 & $9 \times 10^{-12}$ \\
\hline $\mathrm{MgSO}_{4}$ & 260.000 & 738.000 & - \\
\hline $\mathrm{Sr}(\mathrm{OH})_{2}$ & 4.100 & 218.300 & - \\
\hline $\mathrm{SrCO}_{3}$ & 11 & 650 & - \\
\hline
\end{tabular}

Sumber: Droste, R. L (1997) 
Dari penelitian diketahui bahwa $\mathrm{CaCO}_{3}$ dan $\mathrm{Mg}(\mathrm{OH})_{2}$ relatif tidak larut (insoluble) dan pemisahan kesadahan dilakukan dengan pembentukan senyawa tersebut. Secara alamiah, anion bikarbonat cukup banyak di dalam air. Penyebab kesadahan yang dominan ialah kalsium yang dapat dipisahkan dengan pembentukan senyawa $\mathrm{CaCO}_{3}$ dengan berat molekul 100 dan berat ekivalennya 50. Maka, kesadahan biasanya dinyatakan dalam $\mathrm{mg} / \mathrm{l} \mathrm{CaCO}_{3}$.

\section{Proses Kapur-Soda}

Konsep kapur-soda didasarkan pada ide sederhana. Ion penyebab kesadahan bisa dihilangkan (atau dikurangi) kalau diendapkan. Caranya ialah dengan menaikkan $\mathrm{pH}$ air dengan penambahan alkalinitas. Ini akan mengubah bikarbonat menjadi karbonat sehingga terjadi endapan $\mathrm{CaCO}_{3}$ dan $\mathrm{Mg}(\mathrm{OH})_{2}$. Slaked lime merupakan $\mathrm{CaO}$ yang dihidratasi (ditambah air) dan menjadi sumber alkalinitas. $\mathrm{CaO}$ ini juga dikenal dengan nama quicklime. Sodium hidroksida ( $\mathrm{NaOH}$, caustic soda) dapat juga dijadikan sumber alkalinitas. Di bawah ini dituliskan urutan reaksi proses kapur-soda.

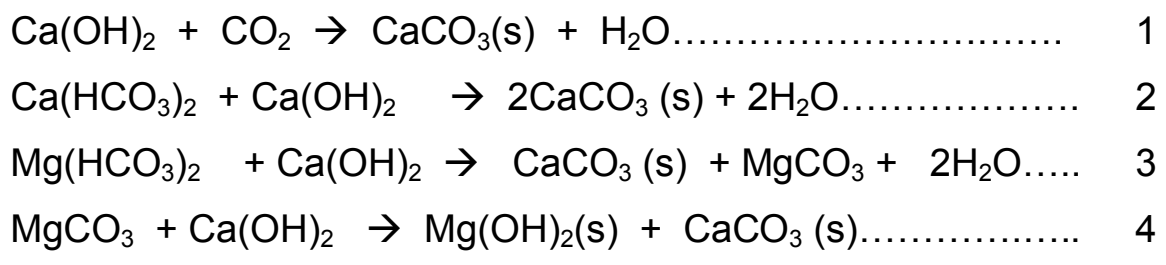

Kehadiran gas $\mathrm{CO}_{2}$ di dalam air ikut mengonsumsi kapur sesuai dengan reaksi di atas. Penambahan kapur menyebabkan peningkatan $\mathrm{pH}$ dan $\mathrm{HCO}_{3}{ }^{-}$diubah menjadi $\mathrm{CO}_{3}{ }^{2-}$ (reaksi 2 dan 3). Kalau penambahan kapur terus dilakukan maka jumlah ion $\mathrm{OH}^{-}$makin banyak lalu terjadilah reaksi 4 dan 6 . Reaksi nomor 7 hanya akan terjadi apabila dibubuhkan soda abu karena ion kalsium dan magnesium berikatan dengan kesadahan non-karbonat. Terakhir, reaksi 3 dan 4 lalu dijumlahkan sehingga diperoleh kebutuhan kapur untuk kesadahan magnesium karbonat.

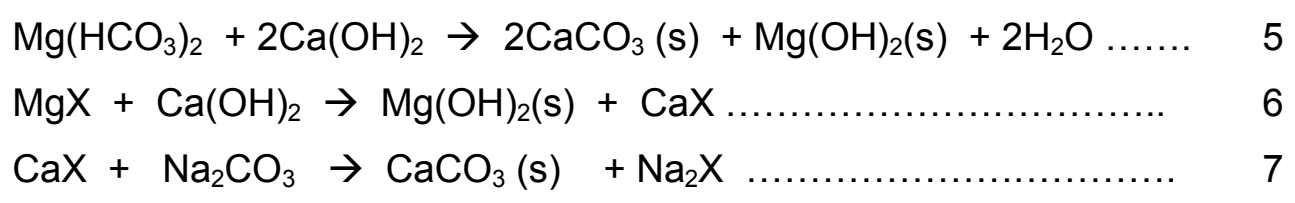


Alkalinitas karbon anorganik bereaksi pertama dengan ion kalsium. Bikarbonat berubah menjadi ion karbonat dengan penambahan alkalinitas lantas terbentuklah $\mathrm{CaCO}_{3}$ yang langsung mengendap. $\mathrm{MgCO}_{3}$ tidak mengendap pada kondisi normal ini tetapi setelah semua bikarbonat berubah menjadi karbonat. Penambahan ion $\mathrm{OH}^{-}$menyebabkan presipitasi $\mathrm{Mg}(\mathrm{OH})_{2}$. Jika diinginkan pemisahan magnesium maka sejumlah kapur harus dibubuhkan untuk mengubah alkalinitasnya menjadi karbonat dan kebutuhan kapur untuk pemisahan magnesium.

Batas terendah untuk pemisahan magnesium ialah $10 \mathrm{mg} / \mathrm{l} \mathrm{CaCO}_{3}$ atau $0,2 \mathrm{mek} / \mathrm{l}$ (milliekivalen perliter). Perlu penambahan kapur berlebih sekitar $35 \mathrm{mg} / \mathrm{l} \mathrm{CaCO}_{3}$ di atas persyaratan stoikiometrik untuk meningkatkan $\mathrm{pH}$ sampai 10,5 agar terjadi presipitasi $\mathrm{Mg}(\mathrm{OH})_{2} \cdot \mathrm{CO}_{2}$ dapat digunakan untuk menurunkan kelebihan kapur dan menurunkan $\mathrm{pH}$ air sampai taraf yang diinginkan seperti reaksi di bawah ini.

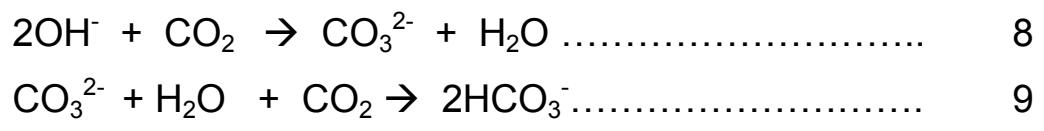

Alternatif lain untuk memisahkan kelebihan ion $\mathrm{Ca}_{2}{ }^{+}$dari pembubuhan kapur berlebih ini ialah dengan penambahan $\mathrm{Na}_{2} \mathrm{CO}_{3}$. Penambahan soda abu ini dilaksanakan bersamaan dengan kapur sebelum masuk ke unit pengendap tempat penampungan endapan $\mathrm{CaCO}_{3}$ dan $\mathrm{Mg}(\mathrm{OH})_{2}$. Kelebihan ion $\mathrm{OH}^{-}$di efluen bak sedimentasi dapat dinetralkan dengan asam klorida sampai nilai $\mathrm{pH}$ yang diinginkan, yaitu airnya stabil (stable water). Cara ini hanya memerlukan satu bak sedimentasi. Itu sebabnya, di dalam instalasi PDAM, unit softening di tempatkan sebelum sedimentasi atau sebelum unit koagulasi-flokulasi agar presipitat yang terbentuk dapat diendapkan bersama dengan kimflok (flok kimia) di unit sedimentasi.

\section{Demineralisasi}

Selanjutnya adalah penerapan teknologi pengurangan kesadahan yang banyak diadopsi oleh pabrik atau industri dalam skala besar, baik untuk air proses maupun sebagai bahan baku dalam proses produksinya dan biasa disebut demineralisasi. Sasaran teknologi ini adalah molekul, atom dan ion berdiameter $10 \mathrm{~nm}, 1 \mathrm{~nm}$, dan 1 Angstrom. Demineralisasi yang bersinonim dengan desalinasi ini dilaksanakan dengan ion exchange dan/atau membran semipermeabel. Hanya saja, kedua unit tersebut perlu air yang bebas koloid, bebas suspended solid, apalagi coarse solid. 
Seperti tersurat pada namanya, demineralisasi dengan ion exchanger (resin) ini bertujuan menghilangkan zat padat terlarut (ionic) di dalam air (dan zat cair lainnya) sehingga banyak diterapkan untuk memurnikan air (purification), tidak sekadar penjernihan (clarification). Purifikasi hanya diterapkan untuk kalangan industri demi memperoleh air bebas mineral sebagai air proses, boiler, atau yang lainnya. Bisa dikatakan, aplikasi utama demineralisasi ialah menyiapkan air berkualitas tinggi untuk umpan (feed water) boiler. Guna lainnya ialah dalam pabrik serat sintetis seperti nylon, rayon, dan kain pada umumnya. Begitu pula pabrik komponen elektronika seperti televisi, komputer, dan farmasi perlu air ultramurni. Bahkan pembangkit listrik tenaga nuklir (PLTN) dan yang berbahan bakar batubara pun perlu proses demineralisasi atas air umpannya.

Khusus untuk air boiler, demineralisasi dilaksanakan dengan ion exchanger yang terdiri atas cation exchanger (catex, penukar kation) dan anion exchanger (anex, penukar anion). Dua jenis atau dua tahap penukar ion inilah yang biasanya dipasang seri di dalam dua kolom terpisah. Air bakunya melewati penukar kation dulu, baru kemudian dilalukan di penukar anion. Tetapi urutan ini bisa saja dibalik, bahkan bisa juga dicampur dalam satu kolom yang disebut mixed bed atau monobed. Artinya, semua susunan resin tersebut memiliki kelebihan sekaligus kekurangan, bergantung pada tahap prosesnya, kualitas media resinnya dan kualitas air baku yang diolahnya.

Ion exchanger tersebut serupa prinsipnya dengan pelunakan air di PDAM. Ion natrium ditukar oleh ion kalsium dan magnesium dalam jumlah yang ekivalen (setara) sehingga hakikatnya tidak terjadi pengurangan jumlah zat padat terlarut (dissolved solid) di dalam air olahan. Oleh sebab itu, kalau air hendak digunakan untuk keperluan boiler atau farmasi, dll maka ion natrium itu tidak boleh lolos ke kompartemen air olahannya. Sebab, baik ion kalsium, magnesium maupun natrium memberikan kontribusi yang sama pada pembentukan zat padat terlarut (dissolved solid). Untuk maksud ini, kationnya lantas diganti dengan ion hidrogen dan ion hidroksida sebagai pengganti anionnya. Ion hidrogen dan hidroksida ini akan bergabung menjadi air $\left(\mathrm{H}_{2} \mathrm{O}\right)$ sehingga tidak ada tambahan padatan terlarut dan tidak mempengaruhi $\mathrm{pH}$.

Satu hal penting, kalau menggunakan air permukaan, maka tahap pengolahan air seperti yang biasa diterapkan di PDAM wajib disertakan untuk melindungi unit ion exchanger dari sumbatan koloid, SS, coarse solid, dan zat organik. Baru selanjutnya dipasang sistem demineralisasi. Sistem ini bisa bermacam-macam urutannya. Opsi yang bisa dan biasa 
dipasang ialah strong dan weak acid cation exchanger, strong dan weak base anion exchanger, mixed bed, decarbonator atau vacuum deaerator. Sebagai contoh, (1) strong acid catex, decarbonator, strong base anex; (2) strong acid catex, weak base anex, decarbonator, strong base anex. Variasi sistem ini dapat dilanjutkan hingga mencapai minimal sepuluh sistem. Kalau digabung dengan jenis unit pengolah lainnya untuk meningkatkan kualitas air olahannya maka jumlahnya akan terus bertambah. Beda urutan dan beda unit yang dipasang akan mempengaruhi kualitas air olahan.

Pengolahan dengan ion exchanger ini minimal dilaksanakan dalam dua tahap. Biasanya kation disisihkan dulu lalu diikuti penyisihan anion. Ion exchange yang mempertukarkan ion di dalam air (larutan) dengan ion lain di dalam media resin banyak diterapkan untuk menurunkan kesadahan dan penyiapan air umpan ketel. Di dalam teknologi pengolahan air limbah, pertukaran ion digunakan untuk menyisihkan logam-logam toksik atau untuk raihan atau recovery metal.

Bahan resin bisa berupa media alami, bisa juga media sintetis. Yang paling banyak diterapkan ialah resin sintetis karena bagus kinerjanya. Resin ialah senyawa hidrokarbon tiga dimensi yang berisi gugus fungsional (contoh gugus fungsi ialah: alkohol, karboksilat, karbonil). Gugus fungsi ini mempengaruhi karakteristik senyawa (campuran) organik dan di sinilah tertambat ion yang dapat ditukar serta larut di dalam air. Sebagai media porus, resin mudah tersumbat (fouling). Ion besi dan mangan, juga koloid, suspended solid dapat menyumbat resin. Apalagi resin dapat dimasukkan sebagai koagulan yang baik bagi zat padat. Oleh sebab itu, konsentrasi padatan sebaiknya kurang dari 2 NTU. Mengacu pada angka ini, maka air yang masuk ke resin akan tampak sangat jernih.

\section{Umpan Ketel}

Air umpan ketel yang tidak memenuhi syarat dapat menimbulkan masalah seperti terjadinya kerak (scale), korosi, dan busa. Kerak dapat terjadi akibat presipitasi padatan dalam air lalu melekat di permukaan dinding ketel. Ini berakibat pada pemanasan lanjut lokal (local overheating) sehingga fungsi logam ketel sebagai konduktor berkurang atau bahkan gagal. Beberapa kerak yang sering terbentuk antara lain: kalsium karbonat (kalsit), kalsium sulfat, magnesium hidroksida, besi oksida, kalsium silikat, magnesium silikat.

Berkenaan dengan korosi, fenomena ini disebabkan oleh $\mathrm{pH}$ airnya terlampau rendah, ada gas oksigen di dalam air, karbondioksida, klor, hidrogen sulfida, dll. Juga adanya garam- 
garam dan zat padat tersuspensi. Oksigen di dalam air, apalagi didukung oleh $\mathrm{pH}$ yang rendah justru dapat menambah proses korosi sehingga logam berubah menjadi bentuk bijih logam dalam proses elektrokimia yang kompleks. Secara umum reaksi korosi bisa ditulis sebagai berikut: $\mathrm{Fe}+2 \mathrm{H}_{2} \mathrm{O} \leftrightarrow \mathrm{Fe}(\mathrm{OH})_{2}+\mathrm{H}_{2}$. Jika diperhatikan dengan seksama, tampak tanda panahnya bermata dua sehingga reaksi ini dinamai reaksi kesetimbangan. Pada suatu saat reaksi tersebut akan "berhenti" karena mencapai titik setimbang sehingga proses korosi pun berhenti. (Sesungguhnya reaksinya tidak pernah berhenti, tetapi terus berlanjut. Hanya saja, konsentrasi ekivalennya tidak berubah, atau konsentrasi yang bereaksi setara dengan yang terbentuk).

Namun demikian, kehadiran gas oksigen di dalam air dan rendah $\mathrm{pH}$-nya menyebabkan gangguan pada reaksi kesetimbangan lalu reaksinya bergeser ke kanan. Pergeseran ini lantas terus melanjutkan proses korosi pada permukaan ketel. Akibat oksigen dan $\mathrm{pH}$ air yang rendah ialah seperti reaksi di bawah ini:

$\mathrm{Fe}(\mathrm{OH})_{2}+\mathrm{O}_{2}+2 \mathrm{H}_{2} \mathrm{O} \rightarrow \mathrm{Fe}(\mathrm{OH})_{3}$

$2 \mathrm{H}_{2}+\mathrm{O}_{2} \leftrightarrow 2 \mathrm{H}_{2} \mathrm{O}$

$\mathrm{Fe}(\mathrm{OH})_{2}+2 \mathrm{H}^{+} \leftrightarrow \mathrm{Fe}^{2+}+2 \mathrm{H}_{2} \mathrm{O}$

Berkaitan dengan penyisihan gas, banyak ragam caranya. Karbondioksida misalnya, bisa dihilangkan dengan cara aerasi (open aerator, degasifier). Adapun oksigen biasanya dihilangkan dengan vacuum deaerator, heater deaerator untuk umpan ketel, penambahan sodium sulfit atau hydrazine. Gas lainnya seperti $\mathrm{H}_{2} \mathrm{~S}, \mathrm{NH}_{3}, \mathrm{CH}_{4}$ bisa dihilangkan dengan aerasi seperti banyak diterapkan di IPAM milik PDAM.

\section{Penutup}

Terapan teknologi pengurangan kesadahan di dalam air sangat variatif, digunakan tidak hanya di PDAM tetapi juga di industri. Malah secara kualitas air olahan, air industri tertentu justru membutuhkan kualitas kesadahan yang sangat rendah, bahkan sampai nol. Jenis teknologi mana yang dipilih bergantung pada tujuan yang diinginkan terhadap air olahan, apakah untuk kebutuhan domestik ataukah untuk kebutuhan industri khusus, dan ini akan berpengaruh pada investasi, biaya operasi dan perawatannya. ${ }^{*}$ 


\section{Daftar Pustaka}

1. Droste, Ronald. L, Theory and Practice of Water \& Wastewater Treatment, John Wiley \& Sons. Inc, 1997.

2. Hammer, Mark J. Water and Waste water Technology, $3^{\text {rd }}$ ed.. John Wiley \& Sons, 1997.

3. Moel, Verberk, Dijk., Drinking Water, World Scientific., 2006.

4. Peavy, Rowe, Tchobanoglous, Environmental Engineering, Mc Graw-Hill, Inc,1985

5. Sawyer, McCarty, Parkin., Chemistry for Environmental Engineering., Mc Graw-Hill., Inc. 1994

Diipublikasikan pada Jurnal Sosioteknologi Terapan, Volume XV, hlm. 39-49, Bulan Maret 2010, ISBN 978-979-17974-4-3 